\title{
Arthur Bispo do Rosário: Narrador benjaminiano de estórias bordadas em diálogo com a literatura infantil e juvenil
}

\author{
Avani Souza Silva ${ }^{1}$
}

RESUMO: Ex-marinheiro, Arthur Bispo do Rosário pode ser visto como uma espécie de narrador benjaminiano. Artesão de narrativas bordadas, sua obra dialoga com o imaginário infantil e com o objeto novo da Literatura Infantil e Juvenil.

ABSTRACT: The ex-mariner Arthur Bispo do Rosário can be seen as a kind of Benjaminian narrator. As a craftsman of embroidery narratives, his work dialogs with the children's imaginary world and the new object of Infantile and Juvenile Literature.

PALAVRAS-CHAVE: narrador benjaminiano; narrativas bordadas; Imaginário infantil KEYWORDS: Benjaminian narrator; embroidery narratives; imaginary world

Para entender a proposta que aqui se apresenta é preciso lembrar-nos de que as narrativas se realizam em suportes expressivos variados e que não se constituem apenas de textos, de palavras. Objetos e imagens colocados em relação também podem construir narrativas, fundamento, não por acaso, da cenografia teatral. É este o pressuposto básico da idéia de que Arthur Bispo do Rosário é um narrador.

Antes, porém, de discorrer sobre o narrador benjaminiano nas obras do artista, importante situá-lo no contexto da arte contemporânea, tentando puxar os fios dos múltiplos diálogos de sua produção para que o narrador que habita a linha de seus bordados possa ter voz.

A biografia de Arthur Bispo do Rosário, no período anterior ao seu reconhecimento público como artista, é contraditória. ${ }^{2}$ Nascido negro e pobre, em Japaratuba (SE), em 1909, antes de ser confinado definitivamente em instituição psiquiátrica, já tinha sido marinheiro da Marinha Mercante Brasileira, funcionário da Light, lutador de boxe, lavador

1 Mestranda em Estudos Comparados de Literaturas de Língua Portuguesa, FFLCH-USP. Pesquisa: Guimarães Rosa e Mia Couto: ecos do imaginário infantil.

2 As informações sobre $\mathrm{o}$ artista e sua obra foram extraídos dos sites http://www.itaucultural.org.br/aplicexternas/enciclopedia_ic/index.cfm?CFID=1855276\&CFTOKEN=906487 52

e http:/www.educacaopublica.rj.gov.br/biblioteca/cultura/cult08a.htm, bem como do livro Por que Duchamp? Leituras duchampianas por artistas e críticos brasileiros, que também reproduzem imagens do acervo de Bispo. 
de ônibus, guarda-costas e mais recentemente empregado doméstico. Nas vésperas do Natal de 1938, teve um delírio místico, julgando-se Jesus Cristo com verdades a dizer aos homens, sendo por isso internado no Hospital Nacional dos Alienados, na Praia Vermelha, no Rio de Janeiro. Um ano depois, estava internado na Colônia Juliano Moreira, em Jacarepaguá, diagnosticado como paranóico-esquizofrênico. Lá ficou internado durante 50 anos, tempo em que teve vários períodos de lucidez, durante os quais saía do hospital para retornar dali a um tempo, em momentos de surtos. Nesses intervalos, ele trabalhava e tinha vida praticamente normal, inclusive produzindo suas obras. A partir de 1969, foi definitivamente internado na Colônia Juliano Moreira, onde permaneceu por mais 20 anos, vindo a morrer aos 80 anos. De volta à Colônia, Bispo reiniciou suas obras numa verdadeira compulsão criativa. Sua produção totaliza mais de 1.000 peças.

Bispo acreditava estar imbuído de uma missão e que era sugestionado por vozes para trabalhar, miniaturizando as coisas da Terra, os objetos do cotidiano, para levar essas representações para o outro mundo no momento do juízo final. Seus trabalhos compõem-se de justaposições de objetos (princípio da acumulação) e de bordados. Nos primeiros, utilizava geralmente objetos de uso cotidiano na Colônia e refugos, tais como canecas, pedaços de pau, de arame, rodos, vassouras, madeira de caixas de frutas, papelões, fios de varal, chapéus, garrafas e materiais diversos obtidos por ele, por outros internos, visitantes e funcionários. Para os bordados, ele usava como suporte colchas, lençóis velhos e jalecos, utilizando as linhas azuis que obtinha desfiando os uniformes dos internos.

$\mathrm{O}$ crítico de arte Frederico Morais proporcionou maior visibilidade às obras de Arthur Bispo do Rosário ao organizar a exposição coletiva “As margens da vida”, realizada no MAM/RJ, em 1982, da qual Bispo participou. Essa exposição desencadeou uma individual de Bispo no mesmo museu e, a partir daí, o projetou nacionalmente. Foi após a

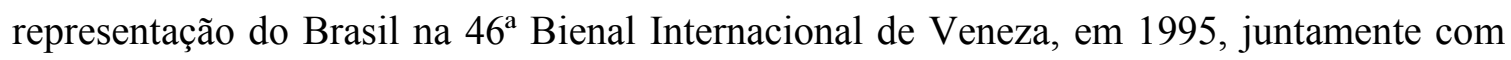
Nuno Ramos, que a obra de Bispo tornou-se conhecida mundialmente. É de ressaltar também que "a recente história da loucura narrada por Foucault e pela antipsiquiatria foi determinante para que os registros de Bispo tivessem meio de pleitear o direito à alteridade", como nos lembra Lisette Lagnado ${ }^{3}$. Neste sentido, o trabalho da Dra. Nise da Silveira foi pioneiro no Brasil, instituindo a Terapia Ocupacional e o exercício da Arte como processos terapêuticos psiquiátricos, contrapondo-se à violência dos métodos

\footnotetext{
${ }^{3}$ LAGNADO, Lisette. Arthur Bispo do Rosário e a instituição, p. 109
} 
tradicionais de tratamento (eletrochoques, lobotomia, coma insulínico etc.). Na esteira dessa nova visão e prática mais humana, foi criado o Museu da Imagem do Inconsciente, que reúne obras de pacientes psiquiátricos.

Bispo produzia suas obras dispondo objetos em painéis de madeira ou papelão, reunidos por similaridades de funções ou de texturas: talheres, canecas de alumínio, colares de pais-de-santo, bonecas de plástico, amuletos e materiais ritualísticos, garrafas plásticas com diversos conteúdos (confetes, pregos, papéis picados, vidros de esmaltes etc.). Ele juntava e amarrava objetos de limpeza (rodos e vassouras) antecipando a construção de instalações dos anos 90. Criou estandartes, cetros, peças de jogos de xadrez, miniaturas, bandeiras e velas, bordou desenhos, nomes de pessoas e de lugares, frases de notícias de jornal ou episódios bíblicos, números, brincadeiras, crianças, representações do cotidiano, cenas urbanas, ambientes de trabalho, guindastes, portos do mundo, barcos, navios etc.

$\mathrm{O}$ artista construiu verdadeiras assemblages, reunindo "objetos geralmente industrializados, produzidos em série, ligados ao consumo e à cultura de massa", 4 a que ele, não por acaso, denominava "vitrines", que eram representações em série desses mesmos elementos, indiciando no nome a própria coisa. São emblemáticas as obras: "Canecas", “Talheres", "Objetos de Limpeza", "20 garrafas, 20 conteúdos", "Sandálias e Peneiras", "Abatjour", "Planeta paraizo dos homens", "Macumba" e tantas outras. Frederico Morais, o crítico de arte que o introduziu no círculo das artes, vinculou sua obra artística à arte de vanguarda, à arte pop, ao novo realismo e especialmente à obra de Marcel Duchamp, um dos ícones do Modernismo, responsável pela subversão do conceito de arte ao utilizar objetos do dia-a-dia, desvinculados de sua função original: o readymade. Para Morais, "O vaso sanitário", "A roda da fortuna", de Bispo, lembram o deslocamento do "Urinol" e "Roda de bicicleta", de Duchamp. Possíveis influências das obras de Duchamp nas de Bispo são totalmente rejeitadas pela maioria dos especialistas. Duchamp era um modernista, artista iconoclasta, enquanto Bispo era um doente mental, desvinculado de qualquer movimento artístico, um outsider, obediente apenas à sua motivação mística. ${ }^{5}$

Entretanto, julgamos não ser possível descartar a eventualidade, mesmo que remota, de Bispo ter tido algum tipo de contato com a obra de Duchamp, folheando revistas, por

\footnotetext{
${ }^{4}$ Morais, Frederico. Texto disponível em:

Http://www.itaucultural.org.br/aplicexternas/enciclopedia_ic/index.cfm?fuseaction=artistas_criticas\&cd_verb ete $=568 \& c d \_i t e m=15 \& c d \_$idioma $=28555$ - acessado em janeiro/2007.

5 Opinião de Lorenzo Aldé no site http://www.educacaopublica.rj.gov.br/biblioteca/cultura/cult08b.htm acessado em agosto/2004.
} 
exemplo, e que isso poderia tê-lo influenciado em alguma medida, no sentido definido por Cianorescu ${ }^{6}$ como relação de contato que possibilita o diálogo entre obras. Bispo refutava a denominação de arte para suas obras e de artista para o seu ser, afirmando que sua obra era uma prestação de contas com Deus. E, todavia, sem ter vivência acadêmica, ateliê, convívio com os meios artísticos, Arthur Bispo do Rosário produziu obras que tiveram forte ressonância na arte conceitual dos anos 80 e 90. Suas obras não apenas remetem às de Duchamp, mas seus estandartes dialogam com os parangolés de Hélio Oiticica, com as obras de Leonilson, que era grande admirador das obras de Bispo, e mais recentemente com os panôs de Hans Made Rasmussen, artista senegalês participante da $26^{\text {a }}$ Bienal Internacional de Arte de São Paulo, somente para citar alguns artistas.

As obras de Arthur Bispo do Rosário estabelecem um diálogo estreito com as ilustrações de livros infantis feitas pela família Dumont, de Pirapora (MG). A partir dos desenhos do filho Demóstenes, mãe e três filhas da família bordam as ilustrações de diversas estórias infantis editadas por grandes editoras: Cia. das Letrinhas, Record, Dimensão, Moderna. Com seus bordados, já ilustraram livros de Ziraldo, Manoel de Barros, Jorge Amado, Thiago de Mello, Rubem Alves, Marina Colassanti e outros, além de seus próprios livros. A estória do bordado remonta à Antigüidade e muitas sociedades se dedicaram a ele. São famosas as tapeçarias do norte da Europa, desde o século XV, os bordados do Irã, de Portugal, da Inglaterra. Há um caráter mágico e lúdico nos bordados, na sua confecção: reuniam-se mulheres para bordar enxovais e peças de vestuário enquanto contavam casos, anedotas, confidências. Seus temas retratam cenas do cotidiano, da natureza, da magia, e são recorrentes na literatura de viagens, na cartografia, na literatura infantil e estão fortemente presentes no imaginário infantil. Quem nunca leu as estórias bordadas nos panos de mesa?

Sem entrar no mérito das ilustrações realizadas a partir de bordados nos livros infantis, na sua previsibilidade e referencialidade e na sua correspondência unívoca com o código escrito, o fato é que os bordados são bonitos e possibilitam-nos fruição estética, remetendo-nos, com sua própria técnica, à representação de cenas domésticas da infância ou do imaginário infantil, imaginário este também presente nos bordados de Bispo.

Os bordados de Arthur Bispo do Rosário contam-nos uma infinidade de estórias. Suas faixas de miss mostram-nas perfiladas no que podemos julgar como a posição clássica

\footnotetext{
${ }^{6}$ Apud NITRINI, Sandra. Literatura Comparada, p. 127
} 
dos finais dos Concursos de Miss que tiveram seu auge nas décadas de 50 e 60. E não bastam apenas as faixas, o autor também nos premia com os cetros que ele constrói em madeira e reveste com linhas. Importante lembrar-nos de que todas as representações de Bispo dirigiam-se a um receptor especial, para quem ele levaria as coisas deste mundo para mostrar-lhe no dia do reencontro: Deus.

O modo com que Bispo inscreve as coisas deste mundo para prestar futuras contas a Deus, para mostrar à divindade o que o homem construiu na Terra e como aplicou o seu tempo, configura a construção de um aparato ilustrativo de seu relato de viagem. Para Walter Benjamin, o narrador nutre suas narrativas de experiências de sua vida e da vida dos outros, e há dois tipos fundamentais de narradores: o viajante e aquele que conhece as histórias e tradições de seu país. Arthur Bispo do Rosário lembra o narrador viajante de que nos fala Walter Benjamin, porém um narrador dimensionado duplamente do ponto de vista espácio-temporal: primeiramente, o marujo do passado que nos conta, no presente, reminiscências de terras distantes, e esse contar presentifica-se nas representações de sua obra, principalmente nos bordados de seus estandartes; e, em segundo lugar, o viajante do futuro, que antecipa no presente o relato que fará a Deus, em terras distantes, das coisas deste mundo, cujas representações ele constrói para ilustrar sua narrativa.

O relato que Bispo espera fazer a Deus é manifestado em diversas obras, como por exemplo, e de forma explícita, na relação de nomes bordada circularmente no forro do "Manto de Apresentação", sua mais importante obra. São nomes de mulheres conhecidas dele, em favor de quem o autor pretende interceder junto a Deus no momento em que se apresentar. Ao carregar seus nomes nas costas, simbolicamente ele carrega essas pessoas e o compromisso íntimo que pactuou com elas de representá-las perante Deus. Sobre essa obra, Ferreira Gullar assim se posicionou:

Se é um manto ou não, pode parecer uma questão sem importância. Não obstante, a designação 'manto' encobre a natureza do arquétipo social sobre o qual Bispo do Rosário elaborou. Esta obra nasce da imitação de uma peça do vestuário da nobreza: parte da roupa de um rei, ou de um general do exército real. Só o paletó interessa, pois nele se concentram os elementos simbólicos ostentatórios de poder e nobreza, como dragonas, bordados, condecorações. (...) o que temos aqui é a apropriação pelo artista de um objeto-símbolo que a seus olhos traduz riqueza, beleza, a nobreza, (...). Vista desse ângulo, esta obra de Bispo do Rosário é, como 
expressão artística, uma manifestação surpreendente por sua originalidade e força semântica. ${ }^{7}$

O manto traz em si a majestade representada pelas insígnias, adornos e dragonas e representa para Bispo, no universo do poder, o mais apropriado vestuário com que um homem eleito, um missionário, possa apresentar-se diante de Deus. As coisas do mundo que o manto carrega em seus bordados são uma mostra do que é a existência terrena. $\mathrm{O}$ manto e a nave, além de sintetizarem a obra artística de Bispo, recolocam a questão da dualidade arte $\mathrm{x}$ loucura e nos apresentam o narrador despedindo-se para sua última viagem:

Quando eu subir, os céus se abrirão e vai recomeçar a contagem do mundo. Vou nessa nave, com esse manto e essas miniaturas que representam a existência. Vou me apresentar. (...) A minha morte se fará notar no mundo inteiro. ${ }^{8}$

Tal como o manto, os estandartes retratam pequenas e grandes estórias. Mostramnos os portos marítimos de vários lugares do mundo, por onde ele andou como marujo da Marinha Mercante Brasileira. Cenas de trabalho no cais nos revelam o cotidiano da atracação: grandes navios, conteiners, guindastes, rebocadores. Navios de carga perfilam-se ao largo com suas bandeiras nacionais. $\mathrm{O}$ artista nos revela, através de seus bordados, esse mundo longínquo de viagens, do além-mar e da chegada ao porto, e até a fala do Comandante. O cotidiano de um só porto que ele borda é a metáfora de todos os demais portos, cujos nomes ele cita. O porto é o lugar de partida e de chegada e tem muita importância para o marujo, porque é nessa área que ele se relaciona com as pessoas que ficam quando ele parte.

De acordo com Walter Benjamin,

A narrativa, que durante tanto tempo floresceu num meio de artesão - no campo, no mar e na cidade - é ela própria, num certo sentido, uma forma artesanal de comunicação. Ela não está interessada em transmitir o "puro em si" da coisa narrada como uma informação ou um relatório. Ela mergulha a coisa na vida do ete $=568 \& c d \_$item $=15 \& c d \_$idioma $=28555$ - Acessado em janeiro de 2007.

${ }^{8}$ Fala emblemática de Arthur Bispo do Rosário, ocupou uma parede da exposição "Imagens do Inconsciente", da Mostra do Redescobrimento do Brasil, realizada no Pavilhão da Bienal, no Parque do Ibirapuera, em São Paulo, de 23 de abril a 7 de setembro de 2000. 
narrador para em seguida retirá-la dele. Assim se imprime na narrativa a marca do narrador, como a mão do oleiro na argila do vaso. ${ }^{9}$

O texto de Bispo traz sua inconfundível marca, em que texto e forma estão indissoluvelmente constituídos: o texto é o bordado, a forma é o bordado. A sua narrativa está de tal maneira impregnada com a sua marca de narrador que, tal como o oleiro de que fala Benjamin, ele é o próprio artesão de sua narrativa.

Benjamin lembra que o dom de ouvir e os próprios ouvintes desapareceram com a sociedade moderna. E se contar histórias sempre foi a arte de contá-las de novo, ela se perde porque ninguém mais fia ou tece enquanto ouve a história. Para Benjamin, a automatização do trabalho já por si faz com que aquele que ouve a história adquira o dom de narrá-la. Mas que essa rede hoje se desfaz por todos os lados, depois de ter sido tecida, há milênios, em torno das mais antigas formas de trabalho manual. No caso específico de Bispo, ele é o artesão solitário que tece manualmente suas próprias estórias: lembranças de viagens, de pessoas conhecidas, de objetos e coisas que existem no mundo e que ele cataloga para recontá-las ao fim de uma outra viagem, já de antemão anunciada, que é a do juízo final, quando ele terá que prestar contas a Deus.

Enquanto a experiência que passa de pessoa a pessoa, de geração a geração, é a fonte a que recorrem todos os narradores, como nos ensina Benjamin, para Bispo o que conta principalmente é sua própria experiência mística. Para Walter Benjamin, há dois tipos de narradores arcaicos que foram os mestres da arte de narrar: o camponês ou trabalhador sedentário e os marujos comerciantes. Para o povo valia a máxima de "quem viaja tem muito que contar" e também aquele trabalhador que nunca saiu de seu país, que trabalhou honestamente e que conhece suas histórias e tradições também tem muito o que contar. Esses dois narradores serão os narradores fundamentais de Benjamin, mas a arte de contar será aperfeiçoada pelos artífices, porque no sistema corporativo medieval haverá interpenetração desses dois tipos de narradores arcaicos. Como o mestre sedentário e os aprendizes migrantes trabalhavam juntos na mesma oficina, lembremo-nos de que cada mestre já tinha sido um aprendiz ambulante antes de se fixar em sua pátria ou no estrangeiro. Segundo Benjamin, esses artífices aperfeiçoarão a arte de narrar, possibilitando no ambiente de trabalho a associação dos conhecimentos distantes trazidos pelos migrantes com o saber do passado, recolhido pelo trabalhador sedentário.

\footnotetext{
${ }^{9}$ BENJAMIN, Walter. O narrador - considerações sobre a obra de Nikolai Leskov, p. 205
} 
Bispo encarna o narrador arcaico de Benjamin na figura do marujo, pois ele é o próprio marujo que vem de terras distantes bordar suas lembranças de viagem para contálas no futuro a alguém, enquanto nos conta essas reminiscências no presente. $\mathrm{O}$ fato de ter sido marujo não faz dele um narrador, mas sim as narrativas de marujo que são reveladas em suas obras. A narrativa de Bispo é icônica, fragmentária, profundamente simbólica, e veicula estórias, experiências de vida e reminiscências de viagens. Por isso, para conferirlhe o estatuto de narrador viajante, como definido por Benjamin, há que se considerar as particularidades do universo psíquico do artista, manifestadas no conjunto de sua obra. Além disso, é preciso não perder de vista que o principal interlocutor desse narrador é Deus, o mesmo que dá fundamento à idéia de narrador onisciente. Sendo onisciente o interlocutor, o narrador tem que ambicionar ao grau máximo de informação com a máxima economia de materiais, modo de produção em que se enquadra "O manto de apresentação". É por essa dimensão desmesuradamente épica que se pode também aproximar o seu lado narrador com a tese do marinheiro benjaminiano.

Arthur Bispo do Rosário é o narrador que vem do mar tornar-se, em terra, artesão de sua própria narrativa. Desfiando uniformes, recolhendo fios azuis e bordando nos lençóis e jaquetões, Bispo narra estórias para adultos e para crianças: como as crianças de seu tempo brincavam de pula-corda, de gangorra, de bola, de ciranda-cirandinha; como as crianças de seu tempo andavam de carrossel. Recriando o universo infantil, com animais domésticos, com as brincadeiras, brinquedos e jogos infantis, Bispo compartilha com o leitor/ouvinte de seu texto suas experiências deste mundo. Neste sentido, seu texto só de imagens dialoga com o objeto novo da Literatura Infantil e Juvenil.

O objeto novo, definido por Maria Lúcia Pimentel de Sampaio Góes, é o livro não essencialmente verbal, mas constituindo-se em um objeto extremamente complexo para o qual convergem diferentes linguagens e tecnologias, criadas pelos multimídias, desde o simples quadrinhos aos mais sofisticados meios eletrônicos. Apresenta-se ainda o objeto novo como brinquedo-livro, jogo-livro, livro de pano, livro só de imagens etc. e exige um novo olhar, multisensível, para descobri-lo. ${ }^{10}$ Seriam os próprios estandartes de Arthur Bispo do Rosário objeto novo?

Walter Benjamin indaga se a relação entre o narrador e sua matéria - a vida humana - não seria ela própria uma relação artesanal. E se não seria tarefa do narrador trabalhar a

\footnotetext{
${ }^{10}$ GÓES, Lúcia Pimentel de Sampaio. Olhar de descoberta.
} 
matéria-prima da experiência - a sua e a dos outros - transformando-a num produto sólido, útil e único. Ele exemplifica o provérbio como a explicitação desse processo, definindo-o como uma espécie de ruína de antigas narrativas. Para nós, a relação artesanal entre o narrador e sua matéria se evidencia em concretude, materializa-se nas próprias obras de Bispo, representações simbólicas de suas experiências de vida e das experiências de vida dos outros, fonte de todos os narradores.

Bispo também incorpora na sua narrativa visual elementos do código verbal, redimensionando o papel do narrador. Ele é o marinheiro que conta para nós, em primeira mão, o que ele contará para Deus. E ele é de tão longe, e está imbuído de tão grande missão, que costurou e bordou para si um belíssimo manto e construiu uma nave especialmente para a sua última viagem para terras distantes do outro mundo, onde será o narrador viajante das coisas que viu aqui.

\section{Referências bibliográficas}

BENJAMIN, Walter. O narrador - considerações sobre a obra de Nikolai Leskov. In: Obras escolhidas, v. 1, São Paulo: Editora Brasiliense, 1986, p. 197-221.

GÓES, Maria Lúcia Pimentel de Sampaio. Olhar de descoberta. São Paulo: Paulinas, 2003.

LAGNADO, Lisette. Arthur Bispo do Rosário e a instituição. In: PAÇO DAS ARTES. Por que Duchamp? - leituras duchampianas por artistas e críticos brasileiros. São Paulo: Coleção Itaú Cultural, 1999, p. 100-113.

NITRINI, Sandra. Literatura Comparada. São Paulo: Edusp, 1997.

PAÇO DAS ARTES. Por que Duchamp? - leituras duchampianas por artistas e críticos brasileiros. São Paulo: Coleção Itaú Cultural, 1999.

\section{Sites:}

http://www.matizesbordadosdumont.com/bordadeiras - Acessado em Agosto/2004

http://www.proa.org/exhibicion/inconsciente/salas/id_salabispo.html - Acessado em Agosto/2004

http://www.itaucultural.org.br/aplicexternas/enciclopedia_ic/index.cfm?CFID=1855276\&CFTOKE $\mathrm{N}=90648752$ - Acessado em janeiro de 2007

http://www.pr.gov.br/mon/exposicoes/bispo.htm - Acessado em março/2007

http://www.educacaopublica.rj.gov.br/biblioteca/cultura/cult08a.htm - Acessado em agosto/2004 